\title{
Distribution of mental health professionals working on site in English and Welsh general practices
}

\author{
Tony Kendrick, Bonnie Sibbald, Julia Addington-Hall, Douglas Brenneman, Paul Freeling
}

\begin{abstract}
Objective-To describe the nature and distribution of mental health professionals working on site in general practices.

Design-Postal questionnaire and telephone interview survey.

Setting-English and Welsh general practices.

Subjects-1880 general practitioners, of whom $1542(82 \%)$ responded.
\end{abstract}

Main outcome measures-Prevalence, types, and distribution of mental health professionals working on site among general practices. Factors predicting the presence of mental health professionals on site.

Results-The number of practices reporting the presence on site of each type of professional were 528 for community psychiatric nurses; 266 for practice counsellors; 177 for clinical psychologists; 132 for psychiatrists; 96 for psychiatric social workers; and 45 for psychotherapists. Mental health professionals tended to cluster together in practices more often than expected by chance alone. Practice characteristics which independently predicted the presence of a mental health professional on site were having four or more partners; being a training practice; and running stress, bereavement, or other mental health clinics. The proportions of practices with mental health professionals on site varied significantly among health regions. There was no association between the presence of mental health professionals on site and the location of practices, the social class mix of patients, or the estimated percentage of elderly patients or patients of nonEuropean origin.

Conclusions-Mental health professionals tend to cluster together, with a preponderance in larger training practices. Specialist mental health care provision within general practices is unevenly distributed. Further research is needed to determine whether this uneven distribution reflects differences in need or inequalities in the provision of mental health services.

\section{Introduction}

Over the past 20 years mental health professionals have tended to move out of hospitals into general practices. In England and Wales more than $20 \%$ of psychiatrists, ${ }^{1} 27 \%$ of clinical psychologists, ${ }^{2}$ and $22 \%$ of community psychiatric nurses ${ }^{3}$ now spend some of their time working in general practice. These arrangements often afford easier access and reduced stigma for patients, with subsequent improvements in attendance and compliance. ${ }^{4}$ Problems may be detected earlier and admissions reduced. ${ }^{56}$

There is, however, concern that the deployment of mental health professionals in primary care may not be targeted to the areas of greatest need and that a lack of coordination may mean that patients with severe illness are neglected. ${ }^{7}$ A survey of six health districts suggests that mental health professionals have preferentially forged links with larger group practices. ${ }^{8}$ Patients of small practices, more prevalent in comparatively disadvantaged areas, ${ }^{9}$ may therefore be further disadvantaged. Some community psychiatric nurses based in primary care have become isolated from mental health teams and have taken on patients with minor disorders directly from general practitioners, at the expense of patients with severe mental illness. ${ }^{10}$

Currently, little is known about the distribution of mental health professionals in general practice and whether these concerns are justified. We report a nationwide survey describing the distribution of these professionals and the factors associated with their presence on site in general practices. The findings should prove helpful to those concerned with planning the provision of psychiatric services in primary care.

\section{Methods}

A sample of about one in 20 general practitioners in England and Wales was selected at random from the Department of Health's records. The sample was stratified by partnership size to include a greater proportion of both singlehanded and larger group practices compared with the national distribution. From this sample we randomly selected 57 of the 98 family health service authorities for inclusion. There was only one general practitioner per practice.

A structured questionnaire was either sent by post or administered as an interview on the telephone. It opened by asking whether any of the following people worked on site in the practice: practice nurse, health visitor, social worker, psychiatrist, community psychiatric nurse, clinical psychologist, practice counsellor, psychotherapist, and psychiatric social worker. Later sections offered a definition of non-directive counselling and asked which staff provided this service. Those who were said to provide counselling and had no other job within the practice were characterised by us as counsellors and their distribution and the nature of their job investigated. ${ }^{11}$ In this paper we describe the distribution of the professionals working on site whose job titles suggested that they provided some type of mental health service.

The questionnaire also covered patient list size; personal list system; whether the practice was a training practice; whether the practice was fundholding; location (urban, suburban, or rural); health region; estimated percentage of patients aged 75 years or over; estimated percentage of patients of nonEuropean origin; social class of patients (mainly nonmanual, mainly manual, or roughly equal); number of partners with a special interest in psychiatry; and number and type of health promotion clinics approved by the family health services authority.
Correspondence to:

$B M F$ 1993;307:544-6

$$
\text { BMJ VOLUME } 307
$$

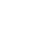


Data were analysed with the statistical package for the social sciences (SPSS/PC+). Whether any one type of professional worked alone or in combination with any of the other types of professional more often than might be expected by chance was assessed by using the $\chi^{2}$ test. The significance of associations between practice characteristics and numbers of mental health professionals on site was assessed by the Mantel-Haenszel test for linear association. Given the large number of comparisons, we report only those findings whose level of significance reached $\mathrm{p}<0.01$, thereby excluding findings of marginal significance, which may have arisen by chance.

To examine the effect of each practice characteristic while controlling for others we used logistic regression analysis. A model was generated including all factors found to be significantly associated with the numbers of mental health professionals on site. The findings are reported as the odds of having a mental health professional on site for a given practice characteristic after controlling for the other characteristics-that is, as the adjusted ratio and $95 \%$ confidence interval. The significance of the effect of health region was estimated by taking the difference in the $\chi^{2}$ values of the logistic regression model with and without the health region fitted.

\section{Results}

Of the 1938 general practitioners contacted, 58 had died, retired, or moved. Of the 1880 presumed still to be in post, 881 completed the postal questionnaire and a further 661 completed the telephone interview. In total therefore, $1542(82 \%)$ of the 1880 general practitioners who were eligible to take part provided usable replies, representing 1542 practices.

The number of practices reporting the presence on site of each type of mental health professional were: 528 for community psychiatric nurses, 266 for practice counsellors, 177 for clinical psychologists, 132 for psychiatrists, 96 for psychiatric social workers, and 45 for psychotherapists. When these prevalences were adjusted for the overrepresentation of both singlehanded and larger group practices in our sample compared with the national distribution of partnership sizes the prevalence of any particular mental health professional changed by no more than $1 \%$. The adjusted figures are therefore not reported.

No mental health professional was reported to be working on site in 726 practices and one was reported in 515; two were reported in 205 , three in 71 , four in 19 , and five in six practices.

Table I shows the numbers of practices with specific combinations of mental health professionals. For each professional the proportion found to be working alone without any other type of mental health professional in the practice was significantly lower than would be expected by chance alone. Instead all types of mental health professionals tended to cluster together in practices.

Factors associated (at the $1 \%$ level of significance) with having higher numbers of mental health professionals working on site included larger patient list size; higher number of partners; being a training practice; having at least one partner with a particular interest in psychiatry; being a fundholding practice; running stress reduction, bereavement, or other mental health care clinics approved by the family health services authority; and the health region in which the practice was located.

There were no significant associations between having higher numbers of mental health professionals on site and whether the practice operated a personal list system or had an urban, suburban, or rural location. There was also no association with the social class mix of patients or the percentage of elderly patients or of patients of non-European origin.

TABLE I-Factors associated with presence on site of mental health professional

\begin{tabular}{lc}
\hline & $\begin{array}{c}\text { Odds ratio of having professional on site } \\
\text { (95\% confidence interval) }\end{array}$ \\
\hline 24 Partmers in practice & $1.44(1.34$ to 1.54$)$ \\
Being a training practice & $1.62(1.38$ to 1.87$)$ \\
Running clinics for: & $2.02(1.77$ to 2.27$)$ \\
Stress reduction & $1.92(1.32$ to 2.52$)$ \\
Bereavement & $1.35(1.06$ to 1.64$)$ \\
Other mental health care &
\end{tabular}

Goodness of fit of model including health region as an additional variable: $X^{2}=1519, \mathrm{df}=1505, \mathrm{p}=0.39$.

Table II shows which of these practice characteristics were independently associated with the presence of a mental health professional on site in the logistic regression analysis. The health region also independently predicted the presence on site of a mental health professional (improvement in model $\chi^{2}$ after fitting health region: $\chi^{2}=48 \cdot 26, \mathrm{df}=14, \mathrm{p}<0.001$ )

\section{Discussion}

Overall, mental health professionals tended to cluster within practices, enhancing opportunities for teamwork and coordination of resources. This was more so for psychiatrists, psychotherapists, and psychiatric social workers, of whom less than a quarter were reported to work in practices with no other mental health professional on site. This clustering probably reflects the fact that mental health professionals usually work together in community mental health teams.

A substantial proportion of practices, however, reported having only one mental health professional on site, most often a community psychiatric nurse, practice counsellor, or clinical psychologist. Though this does not necessarily imply an absence of teamworking among mental health professionals, it

TABLE I-Distribution of specific combinations of mental health professionals on site in 1542 general practices. Values are numbers of practices

\begin{tabular}{|c|c|c|c|c|c|c|c|c|}
\hline & & $\begin{array}{l}\text { Practice } \\
\text { counsellor }\end{array}$ & $\begin{array}{c}\text { Clinical } \\
\text { psychologist }\end{array}$ & Psychiatrist & Psychotherapist & $\begin{array}{l}\text { Psychiatric } \\
\text { social } \\
\text { worker }\end{array}$ & $\begin{array}{l}\text { Any other } \\
\text { mental health } \\
\text { professional }\end{array}$ & $\begin{array}{l}\text { No other } \\
\text { mental health } \\
\text { professional }\end{array}$ \\
\hline Community psychiatric nurse \{ & $\left\{\begin{array}{l}\text { Observed } \\
\text { Expected }\end{array}\right.$ & $\begin{array}{r}101 \\
91\end{array}$ & $\begin{array}{l}96^{\star \star \star} \\
61\end{array}$ & $\begin{array}{l}85^{\star \star \star} \\
45\end{array}$ & $\begin{array}{l}23 \\
15\end{array}$ & $\begin{array}{l}67^{\star \star \star} \\
33\end{array}$ & $\begin{array}{l}253^{\star \star \star} \\
186\end{array}$ & $\begin{array}{l}275^{\star \star \star} \\
342\end{array}$ \\
\hline Practice counsellor & $\left\{\begin{array}{l}\text { Observed } \\
\text { Expected }\end{array}\right.$ & & $\begin{array}{l}40 \\
31\end{array}$ & $\begin{array}{l}29 \\
23\end{array}$ & $\begin{array}{l}22^{\star \star \star} \\
8\end{array}$ & $\begin{array}{l}27^{\star} \\
17\end{array}$ & $\begin{array}{l}139^{\star} \\
119\end{array}$ & $\begin{array}{l}127^{\star} \\
147\end{array}$ \\
\hline Clinical psychologist & $\left\{\begin{array}{l}\text { Observed } \\
\text { Expected }\end{array}\right.$ & & & $\begin{array}{l}31^{\star \star \star} \\
15\end{array}$ & $11^{\star}$ & $\begin{array}{l}18 \\
11\end{array}$ & $\begin{array}{l}120^{\star \star \star} \\
87\end{array}$ & $\begin{array}{l}57 \star \star \star \\
90\end{array}$ \\
\hline Psychiatrist & $\left\{\begin{array}{l}\text { Observed } \\
\text { Expected }\end{array}\right.$ & & & & $\begin{array}{c}12^{\star \star} \\
4\end{array}$ & $\begin{array}{l}20^{\star \star \star} \\
8\end{array}$ & $\begin{array}{l}105^{\star \star \star} \\
68\end{array}$ & $\begin{array}{l}27^{\star \star \star} \\
64\end{array}$ \\
\hline Psychotherapist & $\left\{\begin{array}{l}\text { Observed } \\
\text { Expected }\end{array}\right.$ & & & & & $10^{\star \star \star}$ & $\begin{array}{l}38^{\star \star \star} \\
24\end{array}$ & $21^{7^{\star \star \star}}$ \\
\hline Psychiatric social worker & $\left\{\begin{array}{l}\text { Observed } \\
\text { Expected }\end{array}\right.$ & & & & & & $\begin{array}{l}74^{\star \star \star} \\
50\end{array}$ & $\begin{array}{l}22^{\star \star \star} \\
47\end{array}$ \\
\hline
\end{tabular}

Significance of difference between observed and expected number $\left(\chi^{2}\right.$ test $):{ }^{\star} p<0.01,{ }^{\star \star} p<0.001,{ }^{\star \star \star} p<0.0001$. 


\section{Clinical implications}

- In England and Wales more than $20 \%$ of psychiatrists, $27 \%$ of clinical psychologists, and $22 \%$ of community psychiatric nurses are known to work in general practice

- In this study $8 \cdot 6 \%$ of responding practices reported a psychiatrist to be working on site, $11.5 \%$ a clinical psychologist, $34.2 \%$ a community psychiatric nurse, and $17 \cdot 3 \%$ a practice counsellor

- Mental health professionals were inequitably distributed, tending to cluster in larger training practices

- No association was found between the presence of mental health professionals on site and possible indicators of need, including practice location, social class of patients, and estimated percentage of elderly patients or patients of non-European origin

diminishes the opportunities and raises the possibility of professional isolation.

The factors associated with the presence of a mental health professional on site were perhaps not unexpected. Larger practices are usually better able to generate workload and provide the necessary accommodation. This suggests, however, that patients of larger practices may receive a more accessible service than patients of smaller practices. Training practices tend to be innovative and so are more likely to be in the forefront of recruiting mental health professionals. Running stress reduction, bereavement, and other mental health care clinics is both a possible reason for and a possible outcome of having mental health professionals on site. The variation between health regions in the numbers of professionals on site may be related to differing policies, firstly, of district health authorities on the attachment of professionals to general practices and, secondly, of family health services authorities on the reimbursement of staff employed by a general practitioner. However, much of the variation in the distribution of mental health professionals on site remains unexplained by these factors.

Several possible indicators of a population's need for psychiatric services had no obvious effect on the distribution of on site mental health professionals. They included social class and location (urban, suburban, or rural) and the percentages of elderly and of non-European patients. Our data are based on reporting by general practitioners and are therefore subject to possible inaccuracy. We cannot say whether the distribution of mental health services in general practices reflects needs.

Mental health professionals are unevenly distributed among general practices in England and Wales. Further research is needed to determine whether this unevenness relects variations in need or inequalities in the provision of health services.

We thank the Department of Health for drawing the sample of general practitioners on our behalf; Peter Bower, Fel Oakes, and Lee-Ann Sallis for their help with data collection and handling; and the many general practitioners who participated in the study. The work was funded by a grant from the Mental Health Foundation.

1 Strathdee G, Williams P. A survey of psychiatrists in primary care: the silent growth of a new service. $\{$ R Coll Gen Pract 1984;34:615-8.

2 Hall J, Koch $\mathrm{H}$, Pilling $\mathbf{S}$, Winter $\mathrm{K}$. Health services information and clinical psychology. Bulletin of the British Psychological Society 1986;39:126-30.

3 White E. The third quinquennial national community psychiatric nursing survey. Manchester: University of Manchester, Department of Nursing, 1991.

4 Tyrer P. Psychiatric clinics in general practice: an extension of community care. Br f Psychiatry 1984;145:9-14.

5 Tyrer P, Seivewright N, Wollerton S. General practice psychiatric clinics. Impact on psychiatric services. Br $\mathcal{F}$ Psychiatry 1984;145:15-9.

6 Williams P, Balestrieri M. Psychiatric clinics in general practice-do they reduce admissions? Br f Psychiatry 1989;154:67-71.

7 Goldberg DP. Integrating mental health in primary care. In: Freeman H, Henderson J, eds. Evaluation of comprehensive care of the mentally ill. London: Gaskell, 1991:115-25.

8 Thomas RVR, Corney RH. A survey of links between mental health professionals and general practice in six district health authorities. Br 7 Gen Pract 1992;42:358-61.

9 Jarman B, Bosanquet N. Primary health care in London-changes since the Acheson report. BMf 1992;305:1130-6.

10 Wooff K, Goldberg DP. Further observations on the practice of community care in Salford. Differences between community psychiatric nurses and care in Salford. Differences between community psychiati

11 Sibbald B, Addington-Hall J, Brenneman D, Freeling P. Counselling services on-site within English and Welsh general practices: their nature and distribution. BMF 1993;306:29-33.

(Accepted 14 fune 1993)

\section{PATIENTS WHO CHANGED MY PRACTICE}

\section{Microscopic colitis}

When I was a senior registrar in the mid-'sixties fibreoptics had made little impact on gastrointestinal diagnosis, and, if sigmoidoscopy was required, most physicians (there were few gastroenterologists) would ask a surgeon. We had a teenager with prolonged, disabling but unexplained diarrhoea. An experienced surgeon had pronounced the findings at sigmoidoscopy (under general anaesthesia, of course) to be normal, and the single contrast barium enema showed nothing amiss.

Flexing my newly acquired gastroenterological muscle I performed a rigid sigmoidoscopy, at the same time convincing some sceptical medical students that such things could be done without anaesthesia. I thought the mucosa looked normal, but a study from Leeds confirming the occasional discrepancy between visual changes and microscopic abnormality had just been published. So I took a mucosal biopsy-and indeed the microscopic findings showed undoubted and severe inflammatory change. The patient's response to sulphasalazine was gratifying. That patient changed my subsequent practice so that I unhesitatingly took rectal biopsies in such circumstances. But the story goes on.

Five years later, as a consultant, I was faced with a similar clinical problem, also in a teenager. This time a rectal biopsy was normal, though an air contrast barium enema showed a small area of mucosal irregularity at the splenic flexure. I sought the help of one of the country's first colonoscopists who confirmed minor mucosal changes in the splenic flexure, biopsies of which showed colitis. Over subsequent years the patient developed overt pancolitis. Another lesson learnt.

Nevertheless, only five years ago one of our middle aged nurses with severe diarrhoea eluded diagnosis. Rectal biopsy was normal, and colonoscopy by my clinical assistant was also pronounced normal. I sought help from a colleague, who wisely repeated the colonoscopy, agreed on its normality, but took biopsies. These showed colitic changes patchily in the mid-colon, the symptoms responding to corticosteroids.

These recollections show that I only learn one lesson at a time and that there is always another patient waiting to teach me something new.-JOHN BENNETT is a consultant gastroenterologist in Hull

Watts JMcK, Thompson H, Goligher JC. Sigmoidoscopy and cytology in the detection of microscopic disease of the rectal mucosa in ulcerative colitis. Gut 1966;7:288-94.

We are delighted to receive submissions of up to 600 words on $A$ paper (or patient or book) that changed my practice, $A$ memorable patient, The one message I would like to leave behind, or related topics. 